Omni-Akuatika, 13 (1): 34-42, 2017
ISSN: 1858-3873 print / 2476-9347 online
Research Article

\title{
Sound Characteristics of Terapon Jorbua As Representation to Its Behavior
}

\author{
Amron $^{\left.1^{\star}\right)}$, Adi Lutfi Hanafi ${ }^{1)}$, Indra Jaya ${ }^{2)}$, Totok Hestirianoto ${ }^{2)}$, Karen von Juterzenka ${ }^{2)}$ \\ 1*) Department of Fisheries and Marine, Jenderal Soedirman University, Purwokerto 53122 INDONESIA \\ 2) Department of Marine Science and Technology, Bogor Agricultural University, Bogor 16610 INDONESIA
}

*) Corresponding author: amron@unsoed.ac.id

Received 15 February 2017; Accepted 30 March 2017; Available online 25 May 2017

\begin{abstract}
Types and characteristics of sound that produced by fish is a representation to its behavior. Single click in certain characteristic was produced by Terapon jorbua as representation to its resting behavior, while multiple click that emitted when individual fish was interacted with others. Single frog which had spectral intensity, frequency and duration greater than single click was represented to its territorial behavior. Multiple frog that produced by individual fish was expressed to suffered attack from the other fish or as defensive behavior.
\end{abstract}

Keywords: Sound characteristics, sound productivity, fish behavior

\section{Introduction}

Basically, fish and other aquatic organisms have a life cycle similar to the other terrestrial organisms. However, fish behavior cannot be investigated directly due to the limitations of human vision towards the object in the water column. Several organisms, especially fish which able to produce sound at a specific characteristics (ie frequency and intensity) provides information might be related to their behavior. This information causes the study of fish behavior become more possible to be conducted. Kasumyan (2009) explain that some of acoustic signaling in fish representing their behavior during reproductive, territorial, agonistic, aggressive, social, and feeding behavior. Each of fish species generates different sound characteristic as an expression to their behavior (see Ladich, 2006, Maruska et al., 2007; Jhonston et al., 2008; Fay, 2009; Veerapan et al., 2009; Raffinger and Ladich, 2009; Kilgour et al., 2010).

Mostly, fish sound characteristic generated by anatomy of sound generating organ and mechanism of sound production (Kasumyan, 2008). Stridulation sounds are emitted by rubbing the teeth (Vandewalle et al., 2000), bones of the skull (Colson et al., 1998), and fin rays (Fine and Ladich, 2003). Drumming sounds are caused by contraction and relaxation of sonic muscle (Crawford and Huang, 1999), and swimbladder (Crawford and Huang, 1999;
Lugli et al., 2003). Croaking sounds are produced by pectoral fin (Ladich and Fine, 2006; Ladich, 2007). Pneumatic sounds are occurred when gas released from the swmbladder (Wahlberg and Westerberg, 2003; Wilson et al., 2004). This study aims to investigate the sound characteristics of $T$. jorbua as representation to its behavior.

\section{Material and Method}

Material

Terapon jorbua which is the object in this study was obtained from fishermen in Pelabuhan Ratu Bay, Indian Ocean. The fish was then transported to the laboratory with wet transportation technique, where the fish was packed in a plastic bag containing seawater and oxygen. In the laboratory, fish was acclimatized in big rectangular pond $(5.0 \mathrm{x}$ $0.8 \times 1.0 \mathrm{~m}$; length $\mathrm{x}$ width $\mathrm{x}$ height; water depth $0.7 \mathrm{~m}$ ) that is filled by fully sea water. Sea water circulation and filtration used external water pumps and filters, while aeration system used external air pumps. After one month in the acclimation pond when the fish are able to adapt to both the environment and food, it was then moved into the experimental aquarium. Ten groups of fish in this study were 1 specimen in 50-70, 80-100, and $110-130 \mathrm{~mm}$ (1A, 1B, and 1C), 2 specimen in 50-70, 80-100 and $110-130 \mathrm{~mm}(2 \mathrm{~A}, 2 \mathrm{~B}$, and $2 \mathrm{C})$, and 3 specimen in 50-70, 80-100, 110-130, and combitantion size (3A, 3B, 3C, and 3D). Each 
of group was placed in small aquarium $(50 \times 25$ $\times 30 \mathrm{~cm}$; length $\times$ width $\times$ height; water depth $25 \mathrm{~cm}$ ). Two replications were conducted to minimalize the random error. During the acclimation and experimental period, fish was fed at twice period (morning and dusk) by artificial feed $\left(\right.$ Super-Vit ${ }^{\circledR}$ ), with a chemical composition are moisture $12 \%$; protein $30 \%$; fat $6 \%$; and dietary fiber $6 \%$

\section{Data acquisition}

Video system was used to collect data of fish behavior during resting, territorial, aggressive, and social behavior. The video system has been placed in front of the aquarium. Passive acoustic technique was used to measures sound production of fish along with underwater camera recorded. The hydrophone was positioned in the center of aquarium. Both the video camera and hydrophone was connected to personal computer to record audio and visual signal synchronously.

\section{Data analysis}

Ten sound samples in every hour (24 hours) of each fish group were analyzed by
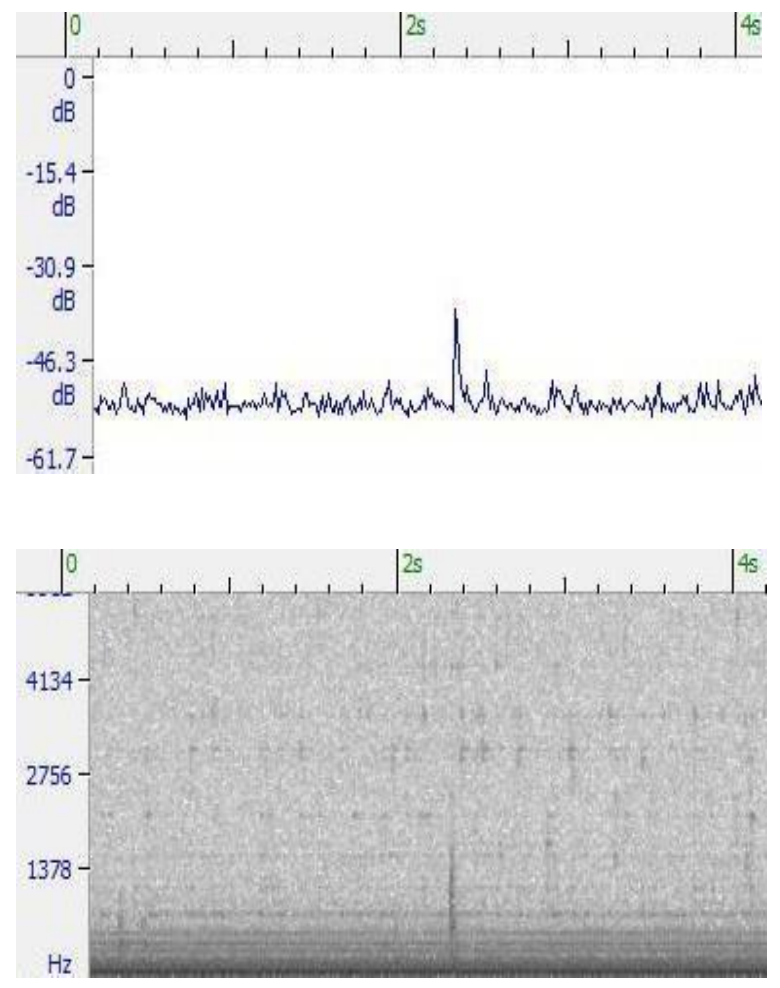

(a)

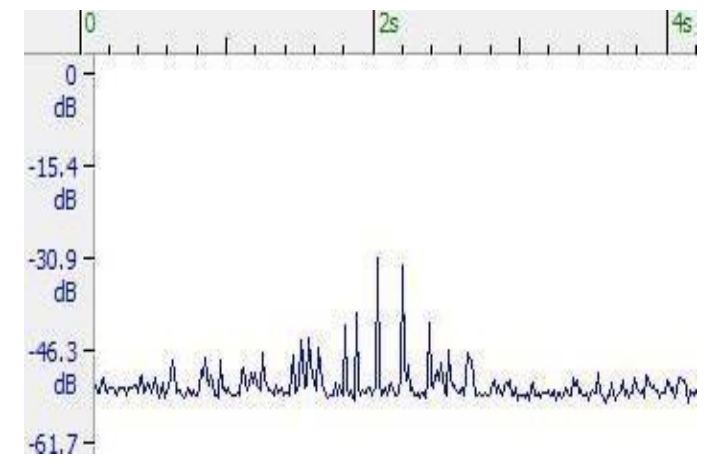

using Two-way Anova to distinguish their sound characteristics. Daily sound productivity and performance behavior of four fish group $(3 \mathrm{~A}, 3 \mathrm{~B}, 3 \mathrm{C}$, and 3D) were analyzed descriptively to explain the domination and productivity of sound as representative of its behavior. Relationship between sound types to the number of attack was analyzed by using simple linear regression model.

\section{Results and Discussion}

\section{Results}

\section{Sound production of T. jorbua}

As other fish species $T$. jorbua also can produce sound with certain types and characteristics. Two main sound types produced by this species, either individual or groups were click and frog sounds (Figure 1). The frog sound had higher intensity, frequency and sound duration characteristic than those of click sound. Both of these sound types could perform single or multiple sounds which certain tone. The single click sound had lower pulse duration compare to frog sound.

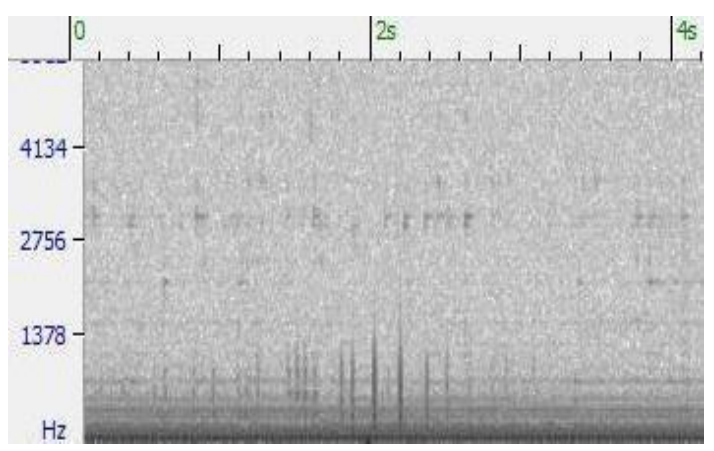

(b) 

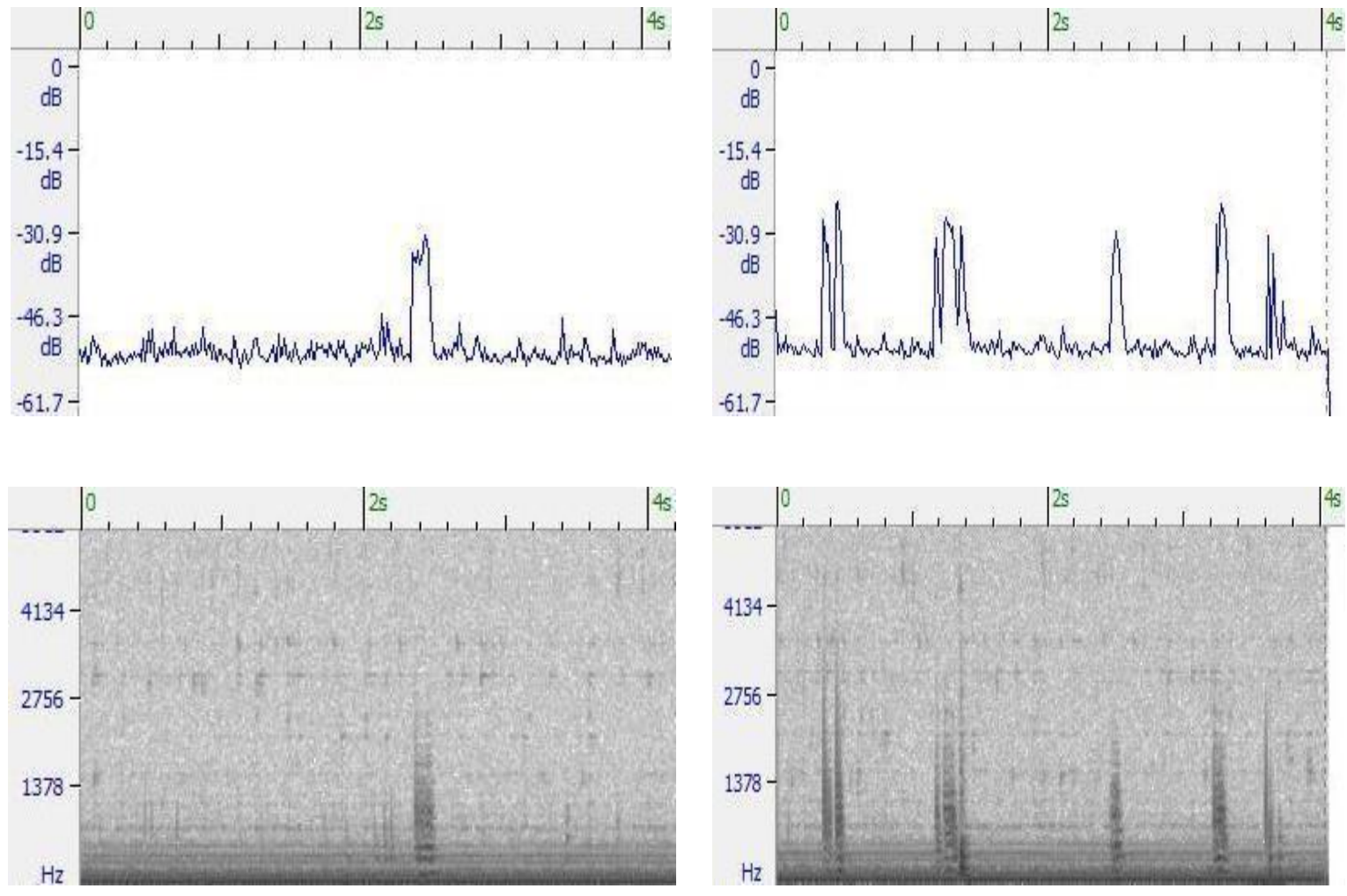

(c)

(d)

Figure 1, Sound type that produced by $T$. jorbua. (a) single click, (b) multiple click, (3) single B, and (d) multiple B. Each of sound type is distinguished by spectral intensity (above) and spectral frequency (below).

Differentiation of each sound characteristic (click and frog sound) could be indicated either as single and group existences or the size condition (Table 1). As an individual, fish produced click sound with certain characteristic based on fish size, meanwhile as group it can produce either click or frog sound. The fish in 80-100 mm size had higher frequency, intensity and duration of click sound compared to other fish size. As a group, the number of fish and fish size influenced the differentiation of sound characteristics. Number of fish in group only influenced to differentiation of frog sound frequency, whereas there was no significant of frequency in click sound. Meanwhile there were no significant in intensity and duration of each fish amount group either click or frog sound. Variation of fish size caused the differentiation of sound characteristic, especially in click sound production. The longer fish size in group had higher click sound intensity, whereas lower in frequency and duration. 
Table 1. Sound characteristics (frequency, spectral intensity, and sound duration) of two sound type (click and frog) that produced by combination of three group of T. jorbua (1, 2, and 3 specimen in an aquarium) and three fish size $(50-70,80-100$, and $110-130 \mathrm{~mm})$.

\begin{tabular}{|c|c|c|c|c|c|c|c|}
\hline \multirow{2}{*}{$\begin{array}{l}\text { Number } \\
\text { of Fish }\end{array}$} & \multirow{2}{*}{$\begin{array}{l}\text { Fish Size } \\
(\mathbf{m m})\end{array}$} & \multicolumn{2}{|c|}{$\begin{array}{c}\text { Frequency } \\
(\mathbf{H z})\end{array}$} & \multicolumn{2}{|c|}{$\underset{\text { (dB) }}{\text { Spectral Intensity }}$} & \multicolumn{2}{|c|}{$\begin{array}{c}\text { Duration } \\
\text { (ms) }\end{array}$} \\
\hline & & Click & Frog & Click & Frog & Click & Frog \\
\hline \multirow{4}{*}{1} & $50-70$ & $2396 \pm 163^{c}$ & - & $-38 \pm 5^{b}$ & - & $55 \pm 27^{\mathrm{bc}}$ & - \\
\hline & $80-100$ & $2755 \pm 262^{c}$ & - & $-31 \pm 3^{c}$ & - & $61 \pm 7^{c}$ & - \\
\hline & $110-130$ & $1710 \pm 141^{a}$ & - & $-41 \pm 3^{a}$ & - & $30 \pm 3^{a}$ & - \\
\hline & $50-70$ & $1807 \pm 118^{a}$ & $2555 \pm 423^{a}$ & $-39 \pm 1^{b}$ & $-32 \pm 3^{a b}$ & $61 \pm 19^{c}$ & $113 \pm 10^{a}$ \\
\hline \multirow[t]{3}{*}{2} & $80-100$ & $1932 \pm 106^{b}$ & $2361 \pm 312^{a}$ & $-39+2^{b}$ & $-33 \pm 3^{b}$ & $29 \pm 7^{a}$ & $112 \pm 13^{a}$ \\
\hline & $110-130$ & $1566 \pm 266^{a}$ & $2806 \pm 109^{b}$ & $-44 \pm 1^{c}$ & $-30 \pm 3^{a b}$ & $28 \pm 4^{a}$ & $164 \pm 28^{b}$ \\
\hline & $50-70$ & $1775 \pm 231^{b}$ & $2800 \pm 104^{b}$ & $-38 \pm 1^{b}$ & $-33 \pm 3^{b}$ & $45 \pm 10^{b}$ & $148 \pm 11^{b}$ \\
\hline 3 & $\begin{array}{l}80-100 \\
110-130\end{array}$ & $\begin{array}{c}1860 \pm 62^{b} \\
1481 \pm 239^{a}\end{array}$ & $\begin{array}{l}2891 \pm 290^{\mathrm{b}} \\
2771 \pm 441^{\mathrm{ab}}\end{array}$ & $\begin{array}{l}-37 \pm 1^{a} \\
-44 \pm 2^{c}\end{array}$ & $\begin{array}{l}-29 \pm 1^{a} \\
-31 \pm 2^{a b}\end{array}$ & $\begin{array}{c}46 \pm 8^{b c} \\
28 \pm 8^{a}\end{array}$ & $\begin{array}{l}147 \pm 33^{b} \\
123 \pm 21^{a}\end{array}$ \\
\hline
\end{tabular}

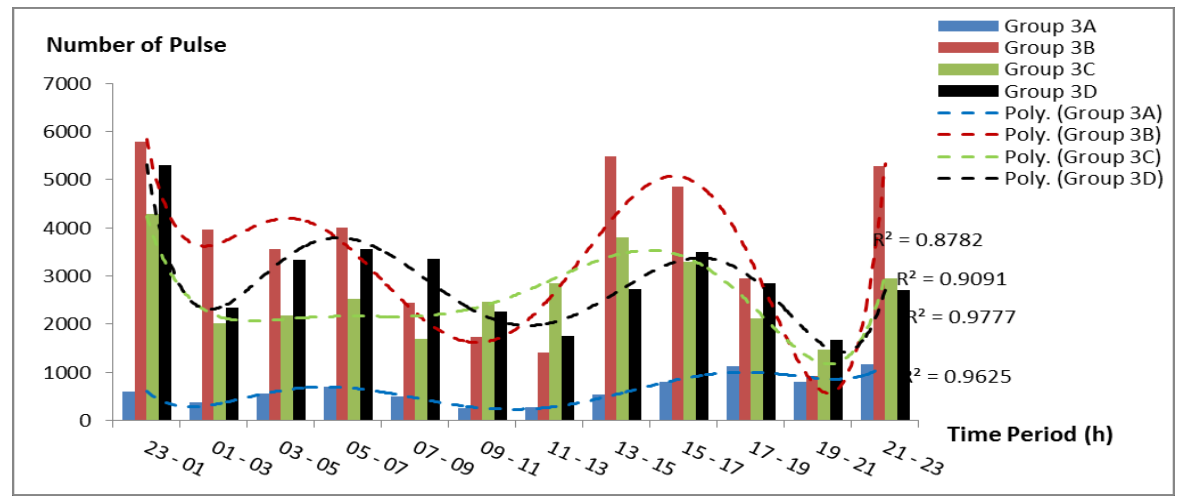

(a)

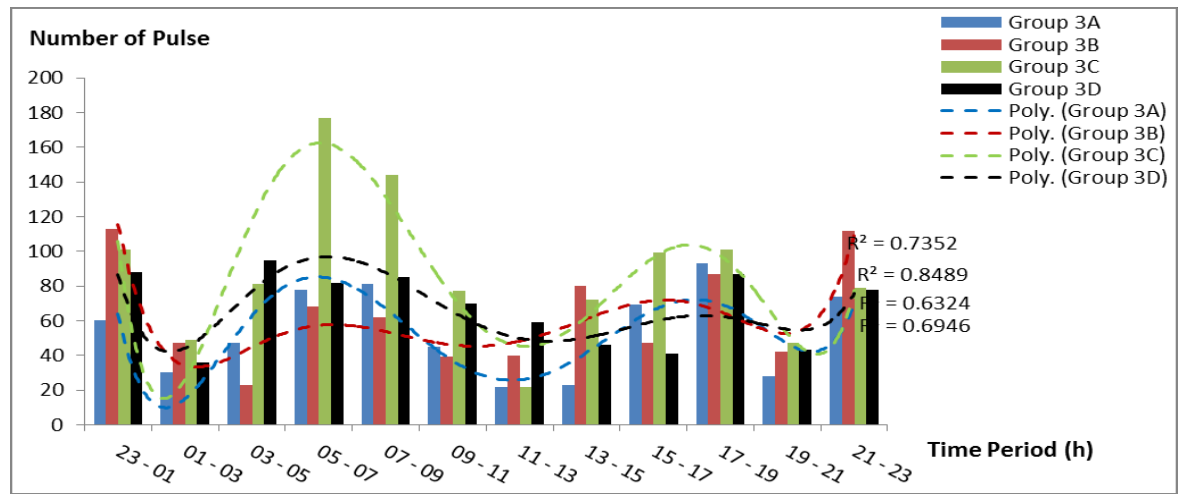

(b)

Figure 2. Daily sound productivity of $T$. jorbua. (a) click, and (b) frog. Blue bar (group 3A), red bar (group 3B), green bar (group 3B), and black bar (group 3D) respectively corresponds to the number of pulse of fish group: 3 specimen in an aquarium with fish size 50-70, 80-100, 110-130 mm, and combination of all size. Blue dot-line (poly 1), red dot-line (poly 2), green dot-line (poly group 3C), and black dot-line (poly group 3D) respectively describes the fluctuation of sound production of each fish group: 3A, 3B, 3C, and 3D. 
Variability of fish size in group not only influenced the sound characteristic, but also determined the daily sound productivity (Figure 2). Differentiation of sound productivity is clearly shown in click sound type, which the fish size group was $50-70 \mathrm{~mm}$. Fish in this group produced less in number of sound compared to fish in $80-100 \mathrm{~mm}, 110-130 \mathrm{~mm}$, and combination size. Even though the click sound production was different between those fish size group but there was simillar pattern of fish daily sound productivity. In the other hand, there were no significant different $(P>0.05)$ both the amount and productivity pattern of frog sound.

Daily sound productivity of each fish size had equal pattern both in click and frog sound. Generally, that both of those sound productions were different in day and night period. Fish actively produced sound in the night period especially near to mid night. Meanwhile sound production was decreased in day period especially near to peak of the day (11 - $13 \mathrm{~h})$. Sound production of fish was rise at both change time, day to night period (17 - $19 \mathrm{~h}$ ) and night to day period (05- $08 \mathrm{~h}$ ).

\section{Sound Characteristics of Their Behavior}

Variation in sound characteristics and sound productivity of fish either at day or night period had related to their behavior (Table 2). Single click was dominantly produced at resting behavior, especially after peak of the day $(13-15 \mathrm{~h})$ and night period (03 - $05 \mathrm{~h})$.
This type of sound was also raising when the fish maintained to their territorial, occured at 09 - 13, 17 - 19, $21-23$ and $01-03$ h. Besides produced single click sound in this period, fish also generated single frog sound as the individual response from the other fish attacked. The multiple click sound was produced by fish as representation its social behavior, especially at $05-07$ and $19-21 \mathrm{~h}$. In this period, it was expressed with the fish playing around with another fish and actively swimming without predatory activity. In the other hand, multiple frog sound was generated as the fish having sporadic predatory activity, especially at $07-09$ and $23-01 \mathrm{~h}$. This type of sound indicated that the response of fish from sporadically attacked by the other fishes.

Aggressive activity between fishes resulted the frog sound productivity, meanwhile it was not significantly influenced to the click sound productivity (Figure $3 a$ and $3 b$ ). Sound production of all fish size group generated increasing sound as well as the rise of predatory activity. It means that frog sound expressed by the individual response of fish from the aggressive activity of the other fishes.

Every aggressive activity has influenced to the number of frog sound, where every one attack activity generated two bound of frog sound. Higher intensity of frog sound did not followed by the increase of click sound (Figure 3c). It strengthens the hypothesis that the predatory fishes did not produced the click sound, however it only generated frog sound.

Table 2, Domination of sound type of each behavior, and time period which are occurred

\begin{tabular}{lcc}
\hline Behavior & Domination of sound type & Time period \\
\hline Interaction behavior & Multiple click & $05.00-07.00$ \\
& & $19.00-21.00$ \\
Territorial behavior & Single click, & $09.00-13.00$ \\
& Single frog & $17.00-19.00$ \\
& & $21.00-23.00$ \\
Aggressive behavior & & $01.00-03.00$ \\
& Multiple frog & \\
Resting behavior & & $07.00-09.00$ \\
& Single click & $23.00-01.00$ \\
& & $13.00-15.00$ \\
\end{tabular}




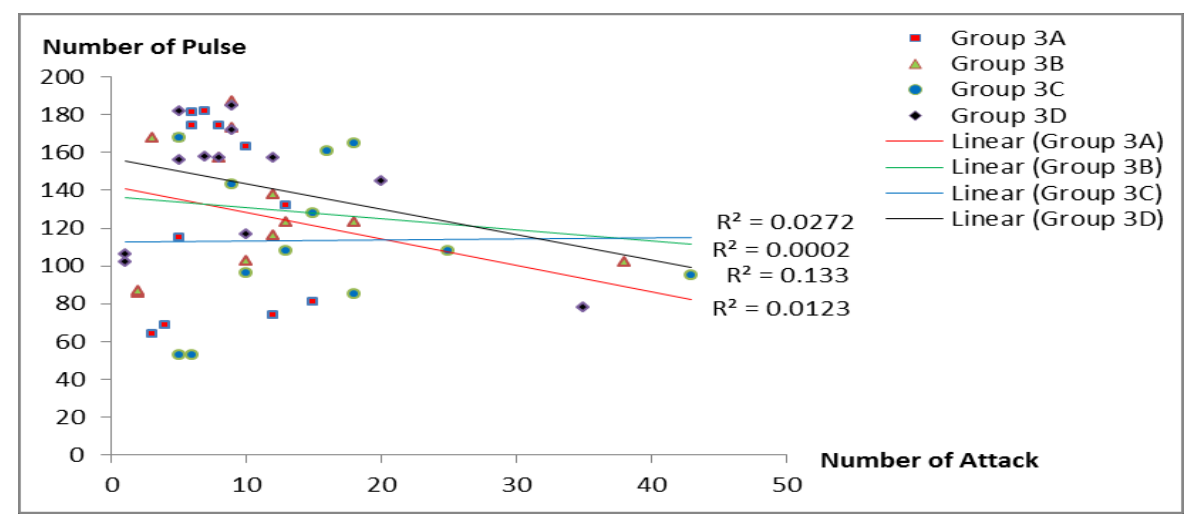

(a)

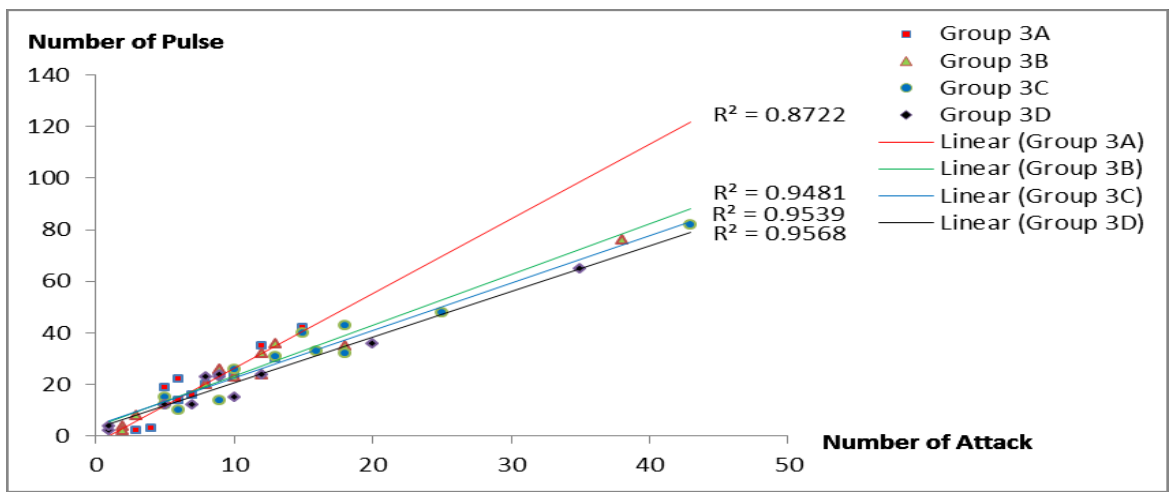

(b)

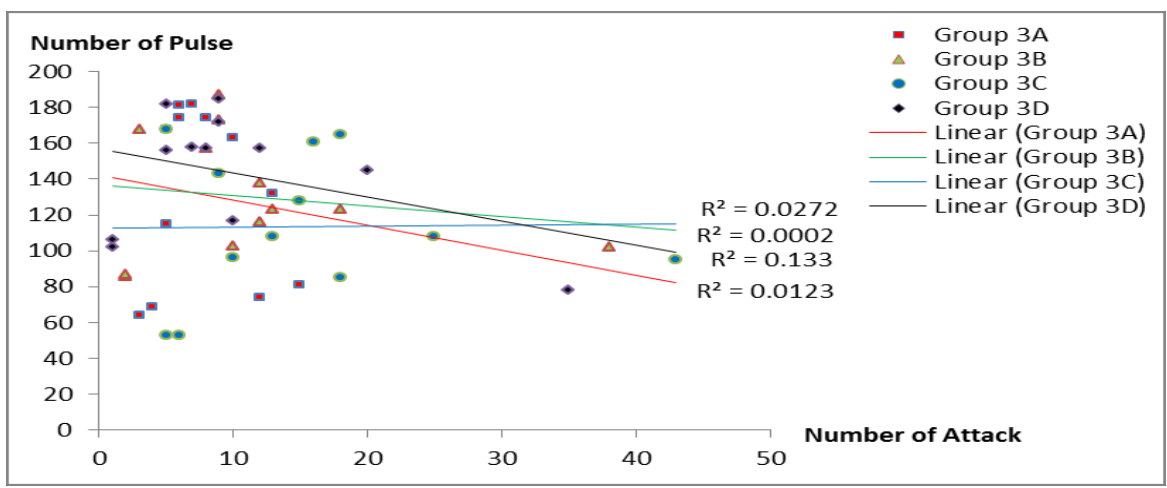

(c)

Figure 3, Relationship between click sound, frog sound, and number of attack. (a) number of attack vs. click sound, (b) number of attack vs. frog sound, and (c) click sound vs. frog sound. Red rectangular (group $3 \mathrm{~A}$ ), green triangle (group $3 \mathrm{~B}$ ), blue circle (group $3 \mathrm{~B}$ ), and black rectangular (group 3D) respectively corresponds to the number of pulse of fish group: 3 specimen in an aquarium with fish size 50-70, 80-100, 110-130 mm, and combination of all size. Red line (poly 1), green line (poly 2), blue line (poly group $3 \mathrm{C}$ ), and black line (poly group 3D) respectively describes the fluctuation of sound production of each fish group: 3A, 3B, 3C, and 3D.

\section{Discussion}

Click sound and frog sound were two sound types which produced by $T$. jorbua. It was generated by pharyngeal teeth and swimbladder (Veerapan et al., 2009). It is not overly much different in terms of sound generating organ and mechanism of sound production with other species of the same genus, i.e. Terapon theraps that have been studied by McCauley and Cato (2000). The growth of fish body has impact to the sound characteristics that they produced. Its caused by the volume of swimbladder is proportion 
increase and has the similar in process of fish growth (Crawford and Huang, 1999). Increase the volume of swimbladder that is consequence of increase of the body size causes the level of acoustic and pulse duration are increase, but the dominant frequency is decrease (Connaughton et al., 2002).

Pulse duration that predicted is increase over the increase of body size; therefore, longer muscles, presumably with longer fibers, are taking longer to complete a twitch in larger fish. Scaling of motion with size in fishes and other animals indicate slower movements in larger animals, implying that the rate of muscle shortening per sarcomere decreases with increasing body size (Wainwright and Barton, 1995). The dominant frequency of sound produced by almost fish is decreases in large fish, which have been shown to have larger swimbladders (Hill et al., 1987). It is argued against a resonance interpretation for a number of reasons. The waveform of acoustic pulses decays rapidly and a pulse is too short to come from a tuned resonator. Decrease of dominant frequency has a correlation to the increase of intensity of fish. Connaugthon et al., (2000) explained that this correlation indicates that the period of the second cycle of acoustic energy, which has the greatest amplitude, is practically identical to the dominant frequency of the call. The minor difference between the calculated and observed frequency can be explained by the effect of the lower amplitude and shorter period of the first cycle, equivalent to a higher frequency of approximately $600 \mathrm{~Hz}$ on the dominant frequency.

The existence of fish as individual and in group has a significant impact on the fish sound characteristics. Fish as individual only emits click sound, and group of fish generate both click and frog sound. The click sound that produced by individual fish has a difference characteristics compare to fish as group. Kasumyan (2009) explained that fish emit sounds in diverse situations in connection with the manifestation of diverse forms of behavior. Click sound by individual fish which is dominated single click represents terrestrial behavior and resting behavior. As group, fish was emitted click with multiple pulse that representing interaction and territorial behavior. Click sound related to the territorial behavior is emitted by fish protecting their sites. In territorial behavior, frog sound in single pulse also produced by another fish as manifestation defensive behavior. In contrast, frog sound in multiple pulses is emitted when fish defended from aggression of another fish.

The fluctuation of sound productivity of fish highly related to their behavior. It is shown by the relationship between daily sound productivity and daily behavior. The click sound that emitted by fish as representing terrestrial behavior dominate the day and night period. During this condition, the fish which own its territory did many demonstrations by surrounds its territory along with producing rapid and loud click sound (Raffinger and Ladich, 2000). The sound which emitted by the fish gave signal to other fishes regarding its territory and as protection to its territory (Valisnki and Rigley, 1981). Click sound in single pulse represented communication behavior which happen near morning and enter night period. The similar sound type also produced while the fish had resting behavior, this condition usually happen after peak of day period and peak of night period. Frog sound production represented defense behavior from attack by other fishes, the peak happened in the morning and near peak of night period. Its sound is a response to stimuli causing in fish fright, stress, shocks, or signal imitating its presence (Myrberg, 1981). At fright, when fish a short time are taken out of water, fish emit sounds with series $2-7$ pulses with a few $\mathrm{Hz}$ and two harmonics (Takayama et al., 2013). Based on this observation, there were no correlations between click and frog sound productivities which emphasized the reason that each resulted sound type as representatives of their behavior. The correlation between the amounts of attack to sound productivity only happens in frog sound, and there was no significant to click sound productivity. The results indicated that every attack which done did not follow by click sound production, hence the attack which happen caused other fishes emitted sound represented defense behavior.

\section{Conclusion}

Types and characteristics of sound that produced by Terapon jorbua represented to its behavior. Single click in certain characteristics was produced when fish is resting, while multiple click that emitted by individual fish when interacting with other individual fish. Single frog which had intensity, frequency and pulse duration which higher than a single click was expressed to its territorial behavior. Multiple frog that produced by individual fish was corresponded to its effort to escaped from attcked of the other individual fish. Some other behaviors that were not observed in this study, such as feeding and spawning behaviors are very interesting to be studied in the future. 


\section{Acknowledgements}

Autrhors great fully acknowledge to Directorate General of Higher Education - Indonesian Ministry of Education and Cultural (Dikti Kemendikbud) for financial support of this research (Hibah Doktor).

\section{References}

Connaughton, M. A., M. H. Taylor, and M. L. Fine, 2000. Effects of Fish Size and Temperature on Weakfish Disturbance Calls: Implications for the Mechanism of Sound Generation. J. Exp. Biol., 203:1503-1512.

Connaughton, M. A., M. L. Fine, and M. H. Taylor, 2002. Use of Sound for Localization of Spawning Weakfish in Delaware Bay (USA) and Effects of Fish Size, Temperature and Season on Sound Parameters. Bioacoustics 12 (23), 294-296.

Colson, D. J., S. N. Patek, L. Brainerd, and S. M. Lewis, 1998. Sound Production During Feeding in Hyppocampus seahorses (Sygnathidae). Environ. Biol. Fish., 51:221- 229.

Crawford, J. D., and X. Huang, 1999. Communication Signals and Sound Production Mechanisms of Mormyrid Electric Fish. J. Exp. Biol., 202:14171426.

Fine, M. L., and F. Ladich, 2003. Sound Production, Spine Locking, and Related Adaptations, in Catfishes, Ed. By Arratia, G., B. G. Kapoor, M. Chardon, and M. Diego. Sci. Publ., Inc., Enfield, Vol. 1, pp. 249-290.

Hill, G. L., M. L. Fine, and J. A. Musick, 1987. Ontogeny of the Sexually Dimorphic Sonic Muscle in Three Sciaenid Species. Copeia, 3:708-713.

Johnston, C. E., M. K. Bolling, D. E. Holt, and C. T. Phillips, 2008. Production of Acoustic Signals During Aggression in Coosa Bass, Micropterus coosae. Environ. Biol. Fishes, 82:17-20.

Kasumyan, A. O., 2008. Sounds and sound production in fishes. J. Ichthyol., 48(11):981-1030.

Kasumyan, A. O., 2009. Acoustic signaling in fish. J. Ichthyol., 49(11):963-1020.

Ladich, F., 2004. Sound Production and Acoustic Communication, in The Senses of Fish. Adaptations for the Reception of Natural Stimuli, Ed. by Von Der Emde G., J. Mogdans, and B. G. Kapoor. New Dehli_Heidelberg, Narosa, pp. 210-230.

Ladich, F., and M. L. Fine, 2006. SoundGenerating Mechanisms in Fishes: A Unique Diversity in Vertebrates, in Communication in Fishes, Ed. by Ladich, F., S. Collin, P. Moller, and B. G. Kapoor. Sci. Publ., Einfield, Vol. 1, pp. 3-43.

Lugli, M., H. Y. Yan, and M. L. Fine, 2003. Acoustic Communication in Two Freshwater Gobies: The Relationship Between Ambient Noise, Hearing Thresholds and Sound Spectrum. J. Comp. Physiol., 189(A): 309-320.

Maruska, K. P., K. S. Boyle, L. R. Dewan, and T. C. Tricas, 2007. Sound Production and Spectral Hearing Sensitivity in the Hawaiian Sergeant Damselfish, Abudefduf abdominalis," J. Exp. Biol., 210: 3990-4004.

McCauley R. D., and D. H. Cato, 2000. Patterns of fish calling in a nearshore environment in the Great Barrier Reef. Phil. Trans. R. Soc. Lond., B 355:12891293.

Myrberg, Jr. A. A., 1981. Sound Communication and Interception in Fishes, in Hearing and Sound Communication in Fishes, Ed. by Popper A. N., and R. R. Fay. Springer, Berlin, pp. 359-426.

Raffinger, E. and F. Ladich, 2009. Acoustic Threat Display and Agonistic Behaviour in the Red Finned Loach Yasuhikotakia modesta. J. Ethol., 27:239-247.

Takayama, M., A. Onuki, A., and T. Yosino, 2003. Sound Characteristics and the Sound Producing System in Silver Sweeper, Pempheris schwenkii (Perciformes: Pempheridae). J. Mar. Ass., 83:1317-1320.

Valinski, W., and L. Rigley, 1981. Function of Sound Production in the Skunk Loach Botia horae (Pisces, Cobitidae). Z. Tierpsychol., 55(2):161-172.

Vandewalle, V., E. Parmentier, and M. Chardon, 2000. The Branchial Basket in Teleost Feeding. Cybium, 24:319-342.

Veerapan, N., Anbalagan, T. \& Balasuramanian T., 2009. Survey on Sound Producing Marine Fishes and Ichthyoplankters of Parangipettai Coastal Waters, Southeast 
Coast of India. American-Eurasian J. Agric. \& Environ. Sci., 6(1):35-40.

Wahlberg, M., and H. Westerberg, 2003. Sounds Produced by Herring (Clupea harengus) Bubble Release. Aquat. Living Resources, 16:271-275.

Wainwright, P. C., and R. C. Barton, 1995. Scaling in the feeding mechanism of the largemouth bass (Micropterus salmoides): motor pattern. J. Exp. Biol., 198:1161-1171.

Wilson, B., R. S. Batty, and L. M. Dill, 2004. Pacific and Atlantic Herring Produce Burst Pulse Sounds. Biol. Sci., 271(Suppl. 3):S95-S97. 